Fecha de recepción: noviembre 2020 Fecha de aprobación: diciembre 2020 Fecha publicación: marzo 2021

\section{Introducción. Interrogantes y respuestas de la Moda en la hipermodernidad. Parte II}

Patricia M. Doria ${ }^{(1)}$

Resumen: En el presente número de Cuadernos del Centro de Estudios en Diseño se analiza la moda, en un contexto de cambio desde sus múltiples aristas desde un complejo y exhaustivo recorrido multidisciplinario. Esta publicación, que se gesta en medio de un cambio trascendental, busca despertar la conciencia de la relación entre la moda como generadora de nuevos interrogantes y su nuevo papel en las sociedades más avanzadas. El Cuaderno discurre en tres miradas. En primer lugar, una mirada orientada particularmente a las variables entre moda y sociedad; una segunda instancia, donde el eje principal es la moda y la cultura y una tercera mirada, que inserta la innovación y el futuro a través de diversos casos.

Palabras clave: moda - sociedad - innovación - cultura - diseño - investigación - arte pandemia - historia - cambio - signo.

[Resúmenes en inglés y portugués en la página 16]

(1) Doctora en Educación Superior (Universidad de Palermo). Magister en Diseño (Universidad de Palermo). Diseñadora de Indumentaria (Universidad de Buenos Aires). Directora del Área Moda y Tendencias de la Universidad de Palermo. Autora del libro, Vestido de Novia: ritual, simbolo y consumo.

\title{
Introducción
}

Este libro "La Moda en su Laberinto. Parte II", se gestó y se concluyó en medio de un cambio trascendental, la pandemia mundial. Estas transformaciones que se introdujeron en el mundo de la moda, tomaron relevancia y visibilidad. Estamos hablando de una de las industrias más importantes del mundo, que fue afectada en su totalidad. En esta publicación se intenta develar el nuevo papel de la moda en las sociedades más avanzadas y afectadas por la pandemia del Coronavirus.

El atravesar la pandemia deja algunos discursos, propuestas, y diálogos obsoletos. Una obsolescencia inmediata, desgarradora y de disenso generalizado. Para aquellos que se han ocupado de observar el mundo de la moda, habrán visto que esta no es superficial, y 
vacía como a menudo parece. González en Pensar la Moda nos indica: “...pero habitualmente se trata de situaciones de crisis. En situaciones normales, la moda se subordina a la conciencia que tenemos de nuestra propia identidad y de nuestra posición en el mundo" (2003, p. 3).

Es decir que estos procesos están involucrados acompañando los procesos sociales, psicológicos, culturales, antropológicos de una sociedad en su conjunto. El interés de esta publicación se inicia, precisamente, en esta nueva perspectiva que intenta entender el nuevo papel de la moda en la sociedad mundial, confundida, desorientada tratando de comprender el nacimiento detrás de la pandemia de un nuevo paradigma.

En momentos de crisis mundial, el sistema de la moda ya ha actuado y ha conectado su sentido de permanencia en forma excepcional dejando un legado y una huella importante en la historia de la moda. Desarrollando un interés más frenético y dinámico por cuestiones que ya venían preocupando a un grupo, y en definitiva la crisis hizo que afectará e involucrará a todos.

Hoy en día la moda se mueve sin cesar hacia formas híbridas de expresión, con necesidad de validación en todos sus aspectos. La moda, la comunicación, el arte y la cultura están íntimamente interconectadas, estamos en un contexto en que se han sacudido los límites y los paradigmas, poniendo énfasis en otras tendencias.

Torrejón, se plantea este nuevo paradigma, en una mutación donde el centro del cambio está puesto, en un cambio de miradas y acciones:

Hablamos de moda y género; moda y regionalismos, moda y compromiso; la circularidad de la moda, su impacto ambiental, el rescate de técnicas ancestrales puestas al servicio de un compromiso de un menor impacto, porque es una industria que tiene mucho impacto, y todo esto son cuestiones muy latentes en este tiempo de pandemia, nos hemos planteado cuánto hemos contribuido con nuestras acciones para que el planeta entre en estos colapsos y cómo sin nosotros la naturaleza se reseteara $(2020$, p. 1$)$.

En el Octavo Arte, Paz Gago (2016), ubica a la moda en el ámbito del arte, y nos indica que, en ese ámbito la moda es testigo de uno de los cambios más significativos en la emergencia, es que, paralelamente a la apariencia legítima, aparecen nuevos comportamientos individuales y colectivos en ruptura con el momento anterior. La mimesis con un otro, para ser aceptado en mi grupo de pertenencia, nos guiaba a usar en forma autoritaria la tendencia, pero la lógica social atravesada por la pandemia, generó una desaceleración. Ya no hay una moda dictatorial sino multiplicidad de modas, igual de legítimas.

Según Simmel (2012), en los proceso de cambio la moda desempeñaba un papel determinante basándose como vimos anteriormente en el mimetismo. Este fenómeno del mimetismo es una manifestación simplista de lo queremos y ambicionamos ser. Supuestamente esta tendencia se encuentra en la base de la sociabilidad humana.

Sartori, explica en su libro La Sociedad Multiétnica que:

El Begriffsbildung, como la construcción conceptual. Históricamente, el concepto de pluralismo se desarrolla a lo largo de la trayectoria que va desde la 
intolerancia a la tolerancia, de la tolerancia al respeto del disenso y después, mediante ese respeto, a creer en el valor de la diversidad (2001, p. 27).

Las perspectivas tradicionales de la moda cambiaron. No se puede llevar adelante una investigación teórica en moda sin proponer teorías, que sirvan de futuras guías de razonamiento. Es decir, generar un constructo, un modelo que sirva de guía de los pensamientos, razonamientos, problemáticas y contradicciones en este gran mundo de la moda. La amplitud de argumentos que transcurren en este escrito, me ha obligado a excluir muchos aspectos dignos de ser tratados, o a realizar ciertas alusiones en torno a ellos.

Estos pensamientos se están dirigiendo hacia formas más agudas y perspicaces, los consumidores eligen por distintas razones los productos, rechazando con decisión la lógica de la diferenciación y buscando en la vestimenta la lógica de la identidad profunda y del compromiso social y ambientalista.

Ahora bien, partimos del supuesto de que existe otra forma de narrar y temporalizar la moda. Sus protagonistas dan comienzo a diferentes sucesos que se desarrollan a través del tiempo. Cada idea, que aparece esbozada o profundamente trabajada en esta publicación, sirve para despertar la conciencia de la relación entre la moda como generadora de nuevos interrogantes; y maravillosamente nos hace ingresar al Laberinto, nuevamente el Hilo de Ariadne adquiere presencia, como hilo conductor, como posibilidad de salida, nos acompaña y ayuda a los lectores de este libro a recorrerlo, comprenderlo, debatirlo, en forma sinuosa, desafiante, considerando los discursos múltiples e inter-dimensionales.

\section{Mirada 1. Moda y Sociedad}

Este eje está compuesto por cuatro artículos centrados en analizar y teorizar sobre la investigación y la sociedad. En este sentido el trabajo de la socióloga italiana Patrizia Calefato titulado: La Moda come Sistema di Segni nel mondo iperconnesso, se centra en el papel de la moda como un sistema transcultural capaz de expresar tensiones, hibridaciones, traducciones, entre los lenguajes del cuerpo, en el contexto de la condición de hiperconexión de la era contemporánea. Este escrito analiza a su vez las transformaciones introducidas en el mundo de la moda ocasionadas por la pandemia del Coronavirus, haciendo especial énfasis en el rol de los medios digitales. El aporte de Valeria Tuozzo y Natalia Lopez en su escrito: Hipermoda, parte II. El entramado psicológico y social de la moda y el género, una perspectiva transdisciplinar, hacen una indagación sobre el cuerpo como protagonista en el acto de vestir, convirtiéndose este en la interfaz que relaciona el interior, los aspectos psíquicos del ello y el superyó, y que se cubren con los ropajes del yo para su presentación pública y social. Puntualmente el trabajo de Jorge Castro, titulado: O. D. S. y su aplicación a la Industria Textil y de la Moda, se enfoca en detallar los contenidos de una nueva agenda que incluya temas muy sensibles, en especial para los países de economías emergentes, como son: reducir las desigualdades en su variedad de dimensiones, generar un desarrollo económico con inclusión, bregar por el trabajo responsable, construcción de ciudades sostenibles, con sistemas productivos, en armonía con el medio ambiente, optimizando 
alianzas entre actores públicos y privados en pro de un desarrollo sostenido. Por su parte, Helga Soto en su escrito titulado: Nuevas encrucijadas en la moda masculina: mirar el pasado para entender el presente, nos describe las nuevas pasarelas shows y un nuevo modelo masculino que si bien parece desafiar originalmente la estética tradicional, en realidad son reversiones de modas pasadas que jugaron con los límites entre los géneros. Este fenómeno particular se inserta en un contexto donde los conceptos de masculino y femenino entran en debate debido a las críticas desde sectores feministas y de la comunidad LGBTIQ+: Lesbianas, Gays, Bisexuales, Trans/Travestis, Intesex y Queer, siendo el siglo “+” un agregado que simboliza las múltiples posibilidades que pueden representar a una persona tanto en su orientación sexual como en su identidad de género con respecto al sistema sexo-genérico.

\section{Mirada 2. Moda y Cultura}

Este eje está compuesto por cuatro artículos centrados en analizar y teorizar sobre la investigación y la cultura, estos conocimientos e ideas atraviesan el simbolismo, la imagen, el pasado, el presente, las narrativas vestimentarias, y el cruce del diseño con las otras artes. En tal sentido el escrito de las diseñadoras Patricia Doria y Eugenia Bailo Donnet, se sumerge en la simbología y su efecto en el arte y la moda con su escrito titulado: $L a$ Ley de la Atracción. Mensajes ocultos, la simbología en moda como lenguaje identitario. El signo, siempre encontró su protagonismo expresivo en la historia de la humanidad, y en la historia de la moda. Estos códigos y mensajes sobrepasan el plano de la lógica/razón y se ubican, en un lugar sensible, cargado de emocionalidad, magia y misterio. Generando una conjunción entre la moda y el arte. Por su parte el aporte de Mónica Incorvaia en su escrito titulado: Fotografía y moda. Aliados indispensables, genera un recorrido contextual sobre lo que la fotografía aportó a la moda como fuente de inspiración para mostrar un mundo glamoroso e innovador. Puntualmente con respecto al escrito de Lorena Pérez, La Moda en el Museo. El caso de la moda Argentina, describe en forma detallada el interés de los museos por la moda y pone en contexto la experiencia de la moda argentina, con referencias a las exhibiciones de Fridl Loos, Dalila Puzzovio, Mary Tapia, Gino Bogani, el movimiento under, la generación de diseño de autor y el caso de Malba Moda a modo de explorar el potencial de la moda en los museos para reflexionar la historia a través de las épocas y sus creadores. En la reflexión de Cecilia Guarás, La cultura como investidura, la historia como subjetividad, incursiona sobre la construcción de la narrativa vestimentaria personal, a partir de la reconstrucción de la historia familiar heredada. Paralelizar el recuerdo y el material tangible poniéndolos en diálogo en un contexto diferente al del hecho en sí, actualizado a través de un receptor contemporáneo. 


\section{Mirada 3. Moda Innovación}

Este eje está compuesto por cinco artículos y se continúa como curso rector reflexionando acerca de la moda, no obstante, el vínculo de análisis se centra en el puente entre moda e innovación, nuevas búsquedas y desafíos. Estos objetos producidos por la moda, abarcan una amplitud que va en sintonía con la disciplina, que busca ser teorizada, se enfatiza la variabilidad de los enfoques desde una reconfiguración multidisciplinaria. En tal sentido María Laura Spina en su artículo, La trama en el espacio tridimensional. La aplicación de un recurso gráfico complementario en el nuevo edificio de la Fondation Louis Vuitton. Explica como actualmente, marcas de indumentaria reconocidas, recurren al dominio del espacio bi-tridimensional con el objetivo de convertirse en símbolos gráficos universales de alto poder de recordación dentro de un espacio urbano. Las autoras españolas Zineb El Habchi Mahir y Graciela Padilla Castillo en su artículo: Futbolistas de élite como instagrammers de moda: Ronaldo y Messi, posicionan a la red social Instagram como un escaparate de moda, la cual cuenta con más de 1.000 millones de usuarios, referenciando Cristiano Ronaldo y Lionel Messi, como dos de los influencers con más seguidores en Instagram. En sintonía con esta propuesta, Sara Peisajovich en su escrito, El arte visual en las tapas de las revistas Vogue y Harper's Bazaar del período de entreguerras. La autora analiza la discursividad y los diferentes sentidos de un conjunto de tapas de revista del período de entreguerras, retomando las cuestiones más significativas de la relación entre las prácticas de las artes visuales, haciendo foco en las primeras vanguardias artísticas, y la moda indumentaria. El análisis audiovisual aparece de la mano de Pablo Tesoriere, con su escrito Comunicación visual en redes, donde sostiene que las redes sociales, con las imágenes, dominan la manera de percibir nuestra realidad consiguiendo condicionarnos a la hora de tomar decisiones. La comunicación visual es una herramienta fundamental de marketing de moda. Por su parte, Yanina Moscoso con su escrito, El rastro de la moda, vuelve a hacer hincapié en el cuidado del medio ambiente y afirma que la moda, como fenómeno social efímero, no desaparece completamente, sino que produce una huella permanente; un rastro que se puede recorrer, un rastro que funciona como testigo y permite identificar patrones, para evaluar y proponer acciones.

\section{Bibliografía}

González, A. M. (2003). Pensar la moda. Recuperado el 14/12/20 de: https://www.academia. edu/1896327/pensar_la_moda

Paz Gago, J. M. (2016). El octavo arte: La moda en la Sociedad Contemporánea. La Coruña: Hércules.

Sartori, G. (2001). La sociedad Multiétnica. Madrid: Grupo Santillana.

Simmel, G. (2012). Filosofía de la Moda. México: Casimiro.

Torrejón, A. (2020). La heteronorma ha sido puesta en jaque. Recuperado el 14/12/20 de: https://www.diariodecuyo.com.ar/espectaculos/La-heteronorma-ha-sido-puesta-en-ja que-20200723-0101.html 


\begin{abstract}
In this issue of Notebooks from the Center for Design Studies, fashion is analyzed in a context of change from its multiple edges from a complex and exhaustive multidisciplinary journey. This publication that takes place in the midst of a momentous change seeks to raise awareness of the relationship between fashion as a generator of new questions and its new role in the most advanced societies. The Notebook runs in three glances. In the first place, a look particularly oriented to the variables between fashion and society, a second instance, where the main axis is fashion and culture and a third look, which inserts innovation and the future through various cases.
\end{abstract}

Keywords:

Keywords: fashion - society - innovation - culture - design - research - art - pandemic history - change - sign.

Resumo: Neste número de Notebooks do Center for Design Studies, a moda é analisada num contexto de mudança desde as suas múltiplas arestas a partir de um percurso multidisciplinar complexo e exaustivo. Esta publicação que se passa em meio a uma mudança marcante busca despertar a consciência sobre a relação entre a moda como geradora de novas questões e seu novo papel nas sociedades mais avançadas. O Notebook funciona em três olhares. Em primeiro lugar, um olhar particularmente orientado para as variáveis entre moda e sociedade, uma segunda instância, onde o eixo principal é a moda e a cultura e um terceiro olhar, que insere a inovação e o futuro através de vários casos.

Palavras chave: moda - sociedade - inovação - cultura - design - pesquisa - arte - pandemia - história - mudança - signo.

[Las traducciones de los abstracts fueron supervisadas por el autor de cada artículo] 